\title{
O Movimento Conservador Norte- Americano da Década de 1950 e a Percepção Conservadora a Respeito da Sociedade, Economia e Política Externa
}

Camila Feix Vidal ${ }^{1}$

Resumo

A política norte-americana recente tem sido caracterizada como polarizada em função de partidos que se afastam do centro do espectro político privilegiando, no caso do Partido Republicano, políticas ultra-conservadoras. Assim, o presente trabalho objetiva analisar o que se convencionou chamar de conservadorismo clássico norte-americano. Busca-se entender o que é o movimento conservador norte-americano através da análise das obras de 4 autores, importantes para que alçasse proeminência no debate intelectual e posteriormente na política: Richard Weaver, Robert Nisbet, Russell Kirk e William Buckley Jr. Percebe-se, ao fim do estudo, que o conservadorismo que surge na década de 1950 pode ser entendido tanto como uma rejeição ao movimento liberal que ascendia nos Estados Unidos desde o século anterior, como uma rejeição ao Comunismo da URSS.

Palvras-chave: Conservadorismo, Estados Unidos, Partido Republicano.

${ }^{1}$ Doutoranda em Ciência Política pela Universidade Federal do Rio Grande do Sul. Bolsista CAPES. E-mail: camilafeixvidal@gmail.com 


\title{
The 1950's North-American Conservative Movement and the Conservative Perception about Society, Economy, and Foreign Affairs
}

\begin{abstract}
North-American politics has been defined as polarized for parties that deviate from the political center emphasizing, as in the case of the Republican Party, ultra-conservative politics. As such, the work here presented intents to analyze the so called North-American classic conservatism. It seeks to understand the conservative movement from the analysis of 4 authors' works, important to launch it in the intellectual debate and, afterwards, in politics: Richard Weaver, Robert Nisbet, Russell Kirk and William Buckley Jr. It is noticed, at the end of the study, that the conservatism that emerges during the 1950's can be understood both as a rejection of the liberal movement that was ascending in the United States since the previous century, and as a rejection against URSS' Communism.
\end{abstract}

Keywords: Conservatism, United States, Republican Party.

\section{Introdução}

A literatura norte-americana vem produzindo trabalhos sobre uma suposta polarização partidária², atribuindo ao partido Democrata uma ideologia extritamente liberal e ao partido Republicano, ao contrário, uma ideologia amplamente conservadora. 0 partido Republicano, no entanto, passou a ser o foco principal desses estudos já que é atribuído a ele um deslocamento

2 PIERSON e HACKER, 2005; STONECASH, 2010; MANN e ORNSTEIN, 2012; LEVENDUSKY, 2009, BREWER e STONECASH, 2009; MCCARTY, POOLE e ROSENTHAL, 2006; FIORINA, 1999, 2005; FIORINA e ABRAMS, 2008; entre outros. 
mais acentudado para o extremo do espectro político direita $\mathrm{x}$ esquerda, no caso, em direção à extrema direita (far-right). De fato, é expressiva a literatura sobre uma suposta mudança ocorrida nesse partido, perceptível na adoção das suas plataformas nacionais e na defesa de determinas políticas, responsável não só por uma polarização partidária, mas por fomentar uma "direita radical” nos Estados Unidos (PIERSON e HACKER, 2005) caracterizada por políticas ultra-conservadoras.

O movimento conservador norte-americano e o partido Republicano não são, entretanto, termos intercambiáveis. Até a década de 1960 esse partido não era reconhecido pela defesa de políticas conservadoras; ao contrário, a diferença ideológica que separava ambos os partidos nos Estados Unidos era mínima, baseada em determinados pontos isolados sendo ambos partidos caracterizados como relativamente liberais. A partir de 1964, com a candidatura de Goldwater a presidência pelo Partido Republicano e, em especial na eleição a presidência de Reagan em 1980, o conservadorismo passou a ser atrelado a esse partido. Até recentemente, a plataforma nacional de Reagan era reconhecida como a mais conservadora de todos os tempos. Princípios conservadores clássicos seriam, de fato, privilegiados nessa presidência. No entanto, eventos recentes, culminando na plataforma do Partido Republicano de 2012, fizeram com que a caracterização da plataforma de Reagan como sendo a mais conservadora da história, fosse questionada. Esse conservadorismo mais acentuado, característico nas plataformas republicanas recentes, ganhou diversos nomes e caracterizações: new absolutism (NISBET, 2003); new conservatism (THOMPSON, 2007); new right (ANSELL, 2001 e COOPER, 2012); compassionate conservatism (PEELE, 2011); conservatism fundamentalist (SULLIVAN, 2006); e radical right (PIERSON e HACKER, 2005). Ainda que receba diferentes nomenclaturas, esse "novo conservadorismo", representado pelo Partido Republicano e cujo ápice é verificado na sua plataforma nacional de 2012, reflete uma concordância: o Partido Republicano parece estar mantendo uma 
O MOVIMENTO CONSERVADOR NORTE-AMERICANO DA DÉCADA DE 1950 E A PERCEPÇÃO CONSERVADORA A RESPEITO DA SOCIEDADE, ECONOMIA E POLÍTICA EXTERNA

agenda política ainda mais conservadora do que a de 1980. Esse conservadorismo mais extremado e responsável pela "guinada à direita” do Partido Republicano, caracteriza-se por políticas ultraconservadoras, tais como aquelas presentes na plataforma republicana de 2012: rejeição sistemática ao aborto; ênfase na família como uma instituição constituída exclusivamente por um homem e uma mulher; apoio irrestrito a Israel; defesa enfática e unilateral dos valores norte-americanos no mundo; rejeição ao estado de bem estar social através da diminuição sistemática do papel e do tamanho do governo na economia norte-americana; entre outras. Essas constatações, no entanto, nos levam a outro questionamento: 0 que é ser "conservador"?

Existem diferentes abordagens sobre o conservadorismo. O conservdorismo é, ao fim, um movimento e, como tal, em constante mutação. As políticas desempenhadas por G. W. Bush no Oriente Médio, por exemplo, são consideradas reflexo da facção neoconservadora, mas são rejeitadas por conservadores clássicos. Robert Nisbet, por exemplo, caracteriza os neoconservadores como anti-conservadores e define o governo W. Bush como um pseudoconservador ${ }^{3}$. Assim, para estudar uma possível radicalização conservadora dentro do Partido Republicano, é necessário, primeiramente, definir o que é o conservadorismo. Optou-se, portanto, pelos conservadores "clássicos" norte-americanos e que tiveram papel fundamental na imposição de uma agenda conservadora dentro do Partido Republicano a partir de 1980. 0 estudo está estruturado da seguinte maneira: inicialmente é feita uma análise sobre as obras de conservadores clássicos da década de 1950 e, posteriormente, uma análise mais específica sobre determinados pontos na política norte-americana e que, de certa maneira, os diferencia da ideologia liberal nos

${ }^{3}$ Para Nisbet (2003, p.64), What is most likely to be labeled "conservative" by the media - and with considerable basis in reality - is militarism on the one hand and Christian Far Right evangelicism on the other. 
Estados Unidos - política externa, política econômica e questões sociais ${ }^{4}$.

\section{A construção do conservadorismo norte-americano}

O movimento conservador norte-americano é relativamente recente. Ainda que o ideal conservador venha a ser antigo (podendo-se caracterizar a própria Revolução Americana como um movimento conservador na medida em que buscava manter os padrões políticos, econômicos e sociais antigos), o conservadorismo como movimento intelectual, bem estruturado e relativamente homogêneo, deu-se na década de 1950 nos estudos de intelectuais norte-americanos. Esses intelectuais favoreceriam, assim, a emergência de posições conservadoras dentro do Partido Republicano, perceptível em 1964 na candidatura de Barry Goldwater (conhecido como Mr. Conservative) à presidência dos Estados Unidos e, em especial, na presidência de Ronald Reagan em 1980, considerado o primeiro governo republicano conservador e uma versão "madura" do conservadorismo de Goldwater (EDWARDS, 2008, p.36).

Inicialmente, o movimento conservador norte-americano é estruturado através das obras de quatro intelectuais: Richard Weaver, William F. Buckley Jr., Robert Nisbet e Russell Kirk 5 . Em apenas cinco anos (1948-1953), esses autores foram responsáveis por dar forma ao conservadorismo norte-americano, servindo de referencial a importantes lideranças republicanas posteriormente (NISBET 1993, BRINKLEY 1994, EDWARDS 2003, NASH,

\footnotetext{
${ }^{4}$ Esses mesmos pontos serviram de orientação na ánalise de plataformas republicanas em um estudo anterior (VIDAL, 2013).

${ }^{5} 0$ Conservadorismo tem sua origem na obra de Edmund Burke, Reflections on the Revolution in France (1790). Ainda que sua obra tenha influenciado os intelectuais conservadores da geração de 1950 dos Estados Unidos, esse trabalho trata exclusivamente do conservadorismo norte-americano, entendido como aquele formulado a partir dos trabalhos de Weaver, Kirk, Buckley Jr. e Nisbet.
} 
O MOVIMENTO CONSERVADOR NORTE-AMERICANO DA DÉCADA DE 1950 E A PERCEPÇÃO CONSERVADORA A RESPEITO DA SOCIEDADE, ECONOMIA E POLÍTICA EXTERNA

2006, SOFFER 2009, e DOUTHAT in NISBET 2010). Ainda que esses trabalhos não lograssem formular um conservadorismo completamente homogêneo, haja vista que deram ênfase a diferentes aspectos nas suas abordagens, eles foram responsáveis por questionar a sociedade, a política e a economia do período vivenciado.

Duas guerras mundiais, armas químicas e nucleares, comunismo, desintegração da família tradicional, New Deal e violência marcavam o período nos Estados Unidos. Valores tradicionais eram abandonados e a ciência tomava o lugar da fé e da "moralidade". Nesse contexto, o que esses autores buscavam exprimir era um descontentamento geral com a situação vivenciada, seja ela política, social ou econômica; seja ela no plano global, nacional ou local. Para esses autores, a modernidade e a ciência não pareciam ter efeitos benéficos para a sociedade; em última análise, o progresso e a ciência foram responsáveis por efeitos perversos, como a bomba nuclear. Daí a necessidade da busca por valores tradicionais norte-americanos, responsáveis por uma sociedade "moral" e, consequentemente, melhor do que a sociedade do pós-guerra, da ciência e do New Deal. 0 que de fato os unia, portanto, era, no plano político, a aversão ao comunismo; no plano econômico, a aversão ao Keynesianismo e às políticas liberais de bem estar social; ${ }^{6}$ e no plano social, a busca pela retomada da religião e de valores tradicionais norte-americanos. Em síntese, essas seriam as características fundamentais do conservadorismo norte-americano presente na década de 1950, chamado, nesse trabalho, de conservadorismo clássico.

0 primeiro trabalho moderno a promover o ideal conservador nos Estados Unidos foi o de Richard Weaver em 1948, Ideas have consequences. Nessa obra, o autor estuda as causas e os efeitos

\footnotetext{
${ }^{6}$ A caracterização de "liberal" refere-se, no contexto norte-americano, a práticas de políticas de bem estar social, tal como tradicionalmente defendida pelo Partido Democrata, baseadas no papel chave do Estado na formulação, implementação e defesa de políticas de bem estar social. No pós guerra, essa noção seria relacionada com políticas econômicas Keynesianas.
} 
da decadência das crenças nos princípios e valores da sociedade norte-americana que culminaram na "dissolução do Ocidente" (WEAVER, 2008). Nele, Weaver atenta para a importância da crença como condutora de decisões sábias e do papel da racionalidade científica como método de dominação. Dessa maneira, os problemas enfrentados pela sociedade naquele momento eram resultado de decisões tomadas sem o uso da inteligência e da crença, caracterizados por uma racionalidade científica. A dissolução do Ocidente significaria um abismo moral e religioso, suplantado pelo racionalismo e ciência. A alternativa seria maior ênfase na moralidade em contraste com a cientificidade: tenho a ousadia de propor, se não uma solução integral, ao menos parte de uma solução, a convicção de que as análises científicas não valem nada quando vão acompanhadas de impotência moral (Ibidem, 1. 297).

Na tentativa de conter a dissolução do Ocidente, Weaver aponta o primeiro passo a ser tomado: distinguir o "bom" do "ruim". Os valores tradicionais da humanidade (ocidental) teriam desaparecido, sendo suplantados pelos princípios emanados da ciência. A ciência, atribuindo a existência à soma de toda natureza física, definiria o homem como naturalmente bom, sendo seus defeitos derivados da ignorância ou do ambiente. Assim, o evil não teria espaço, nem significado, na caracterização da humanidade; a religião perde sentido; e a preocupação moral por uma vida além da material é suplantada pela preocupação com o saber científico. Dessa maneira, Weaver atenta para a necessidade de: 1) reverter a decadência do ocidente; e 2) restaurar a inteligência humana, a crença e a moralidade - capaz de distinguir entre o "bom" e o "ruim" (good x evil).

A "cultura da ciência" seria responsável por um desejo de imediação, preocupada com o agora, o visível, e o mais próximo. Os

${ }^{7}$ As citações das obras utilizadas via Kindle que não são paginadas, são feitas com a indicação da localização (l). 
O MOVIMENTO CONSERVADOR NORTE-AMERICANO DA DÉCADA DE 1950 E A PERCEPÇÃO CONSERVADORA A RESPEITO DA SOCIEDADE, ECONOMIA E POLITICA EXTERNA

relacionamentos, nesse sentido, seriam caracterizados por uma busca de vantagens no presente. Laços familiares e comunitários poderiam, portanto, vir a perder espaço em um mundo onde o que vale não é a tradição, a moral, ou os meios para se chegar a determinado fim; mas o presente, o material e os fins. 0 homem racional estaria preocupado com os seus direitos, mas não com as suas obrigações; com as partes, mas não com todo; e com o material imediato, mas não com o espiritual de longo prazo. Em suma, o homem racional seria um egoísta materialista. Weaver defende, ainda, uma ordem social hierárquica, cuja distinção seria baseada no conhecimento e na virtude. Sendo os homens naturalmente diferentes entre si, caberia uma diferença social também. A justiça, assim, seria que cada um recebesse o que efetivamente merece de acordo com o seu conhecimento e virtude. A igualdade entre homens seria responsável por um caos social na mesma medida em que a igualdade entre pai e filho resultaria em fracasso familiar. Da mesma maneira, a distribuição de recursos pelo governo para homens que não o mereceriam (não possuem a virtude ou o conhecimento necessário para maior elevação social), os transformaria em homens mimados, sem habilidade para pensar ou viver por si próprio (Ibidem, l. 204). A igualdade é preferível, no entanto, na "distribuição" de conhecimento e de valores. A fragmentação do conhecimento e a decadência dos valores tradicionais seriam responsáveis por uma sociedade caótica. Assim, Weaver advoga para que todos bebam da mesma fonte: a religião.

O segundo trabalho pertencente a "onda conservadora" da década de 1950 e fundamental para o desenvolvimento do conservadorismo norte-americano foi o de William F. Buckley Jr.: God and Man at Yale (1951). Por meio de uma análise das estruturas sociais, políticas e econômicas em Yale que, naquele período, visavam uma maior abertura e liberdade acadêmica ${ }^{8}$, Buckley Jr.,

${ }^{8}$ A "abertura acadêmica" significa a liberdade que um professor recebia para ensinar what he sees fit as he sees fit desde que provasse honestidade e competência professional (BUCKLEY JR., l. 751). 
então estudante de Yale, argumenta que: 1) Yale estava enfraquecendo, propositalmente, a fé Cristã dos seus alunos; 2) Yale estava promovendo coletivização econômica - Keynesianismo; e 3) Antigos alunos da Yale deveriam reverter essa tendência na universidade negando ajuda financeira até que a universidade restringisse a liberdade acadêmica para que a religião (Cristã) e a liberdade política e econômica pudessem sempre prevalecer (BUCKLEY JR., 2001).

A crítica, no entanto, não se restringia à Yale, mas à sociedade em geral. A "abertura" da universidade era reflexo da "abertura" da sociedade, cada vez mais secular e igualitária. A sociedade aberta estaria plantando as sementes para o totalitarismo, já que esse aconteceria a partir de uma rejeição a Deus e, por conseguinte, uma rejeição a qualquer autoridade nas instituições humanas, tais como família, igreja e mercado. Assim, para uma sociedade ser "livre", ela requereria tradição Cristã no âmbito social e hierarquias no âmbito econômico. Associando religião, política e economia, Buckley Jr. argumenta que: the duel between Christianity and atheism is the most important in the world. I further believe that the struggle between individualism ${ }^{9}$ and collectivism is the same struggle reproduced on another level (BUKLEY JR., 2001, 1. 786).

A tentativa de Buckley Jr. em reverter o secularismo, o Keynesianismo (na obra, associado com o coletivismo) e a liberdade acadêmica de Yale; faz parte de uma tentativa maior: a da transformação da sociedade. Em um momento de desintegração social, fraqueza política e caos econômico, se torna essencial, para o autor, o retorno a uma sociedade Cristã, a uma economia de livre mercado e a uma política onde os preceitos religiosos tenham

\footnotetext{
${ }^{9}$ No prefácio da edição de 2001, Buckley Jr. explica que, na época em que foi escrita a obra, "individualismo" se referia tão somente ao âmbito econômico, significando o contrário de "coletivismo". Se reescrita, o autor trocaria "individualismo" por um sentido mais amplo como "conservadorismo".
} 
O MOVIMENTO CONSERVADOR NORTE-AMERICANO DA DÉCADA DE 1950 E A PERCEPÇÃO CONSERVADORA A RESPEITO DA SOCIEDADE, ECONOMIA E POLÍTICA EXTERNA

espaço. Infere-se, portanto, a noção de hierarquização social e de justiça econômica conforme méritos pessoais, como condicionantes dessa sociedade proposta pelo autor, indo ao encontro das mesmas prerrogativas argumentadas por Weaver, três anos antes.

A ênfase na religião, no livre mercado e na tradição como preceitos para uma sociedade melhor também são encontrados na obra de Russell Kirk, The Conservative Mind (1953). A importância desse trabalho é mister para o conservadorismo norte-americano. Até esse momento as noções de conservadorismo, ainda que visíveis nos trabalhos supracitados, se encontravam fragmentadas. Pela primeira vez o conceito de conservadorismo é exposto e estudado em grande profundidade através de uma análise histórica e bibliográfica (dando ênfase ao trabalho de Edmund Burke). 0 conservadorismo é, assim, defnido como um movimento em transformação, re-expressing their convictions to fit the time. A essência conservadora, no entanto, permanece sempre a mesma, qual seja, a preservação da tradição moral da humanidade (KIRK, 1953, p.7).

Em uma tentativa de elencar princípios conservadores comuns, Kirk formula os seis pilares do pensamento conservador:

1) Belief that a divine intent rules society as well as conscience, forging an eternal chain of right and duty (...). Political problems, at bottom, are religious and moral problems;

2) Affection for the proliferating variety and mystery of traditional life;

3) Conviction that civilized society requires orders and classes. The only true equality is moral equality;

4) Persuasion that property and freedom are inseparably connected. Separate property from private possession, and liberty is erased; 
5) Faith in prescription and distrust of "sophisters and calculators". Tradition and sound prejudice provide checks upon man's anarchic impulse;

6) Recognition that change and reform are not identical, and that innovation is a devouring conflagration more often than it is a torch of progress. Society must alter, for slow changes is the means of its conservation; but Providence is the proper instrument for change (Ibidem, p.7-8).

A humanidade, de acordo com Kirk, estaria indo contra os princípios conservadores na medida em que busca a igualdade econômica; promove o nivelamento político baseado na proibição de ordem e de privilégios; demonstra desprezo pela tradição e rejeição a religião formal; e mantém uma visão do homem como um ser perfeito, sendo o evil um fator externo. Não só o homem não é perfeito, ele padece de impulsos que se traduzem na busca por poder; como também essa imperfeição e a ordem social que dela resulta é natural devendo, assim, ser mantida. A religião, nesse sentido, tem o poder de consolar os que padecem da imperfeição ao mesmo tempo em que limita os impulsos negativos da humanidade (Ibidem, p.31). Além da religião, a moralidade e a tradição restringiriam os impulsos e os apetites voracious and sanguinary dos homens, haja vista que a razão, por si própria, nunca consegue impor certas obrigações morais (Ibidem, p.39). Nesse sentido, Kirk ainda aponta para a prudência como uma virtude essencial. Faz-se necessário olhar o todo, e não as partes, e agir com cautela, já que a humanidade possui um aspecto evil intrínseco.

Uma importante contribuição de Kirk é a sua crítica ao Keynesianismo, e ao coletivismo em geral, relacionando-a e legitimando-a na religião. Segundo Kirk, Equal justice is indeed a natural right; but equal dividend is no right at all. The laws of nature, ordained by Divine wisdom, make no provision for sharing goods without regard for individual energies or merits (Ibidem, p.48). Na natureza, os homens são desiguais em todos os aspectos (corpo, energia, capacidades, etc.), infere-se, portanto, que a hierarqui- 
O MOVIMENTO CONSERVADOR NORTE-AMERICANO DA DÉCADA DE 1950 E A PERCEPÇÃO CONSERVADORA A RESPEITO DA SOCIEDADE, ECONOMIA E POLÍTICA EXTERNA

zação e as desigualdades econômica e social são fatores naturais que ordenam a sociedade. A obra de Kirk, ao debruçar-se sobre o conservadorismo propriamente dito, é essencial para que esse tomasse forma como movimento relativamente homogêneo e, como consequência, se difundisse nas universidades, na sociedade e na política.

Se a obra de Kirk foi importante para a conceituação e consolidação do conservadorismo nos Estados Unidos, o trabalho de Robert Nisbet foi essencial para levar esse movimento na política norte-americana, em especial, no Partido Republicano. Quest for Community (1953) foi a primeira obra importante de Nisbet, que mais tarde passaria a escrever artigos, livros e estudos sobre o conservadorismo e que influenciariam o governo de Reagan, G.H.W.Bush e G.W.Bush (DOUTHAT in NISBET, 2010, l. 157). Assim como Weaver, Buckley Jr. e Kirk, Nisbet também buscava explicar como a sociedade moderna, com seu apelo científico e racional, foi capaz de experimentar as tragédias de duas guerras mundiais, campos de concentração, bombas atômicas, entre outros evils. A resposta, para Nisbet, é a dimensão local, ou seja, a importância da comunidade.

A aparente contradição entre a ideologia pregada pela modernidade, baseada em laissez-faire e em liberdades, e a realidade presente no totalitarismo de Mussolini e Hitler, fazia sentido. Para Nisbet, o homem é um ser social. Assim, ele precisa satisfazer sua necessidade de pertencimento, de aceitação e de participação de alguma maneira. Até o advento da sociedade moderna, o homem satisfazia essa necessidade nas escalas locais de associações: famílias, igrejas, associações comunitárias, entre outros. Com o advento da modernidade, no entanto, essas instituições teriam perdido espaço e, com isso, deixado um vácuo de autoridade. 0 indivíduo buscaria, no Estado, a autoridade moral que antes pertencia ao espaço local. Assim, o liberalismo seria responsável por trazer, como consequência, o totalitarismo já que, ao tomar para si atividades antes desenvolvidas pelas co- 
munidades e instituições locais, produz indivíduos "emancipados" que vão satisfazer suas necessidades sociais em um âmbito federal. Dessa maneira, o totalitarismo tal como presenciado durante a Segunda Guerra Mundial só foi possível por conta da perda, por parte dos indivíduos, das alianças e comunidades com as quais eram acostumados e delas faziam parte. Assim, the expansion of power feeds on the quest for community (Ibidem, l. 265)

Para Nisbet, a citação de Proudhon: Multiply your associations and be free (Ibidem, l. 369) reflete o projeto central do conservadorismo norte-americano. Nesse sentido, não é a busca por emancipação humana frente ao Estado totalitário, mas a defesa do indivíduo e de seu grupo, seja ele a igreja, a família ou a comunidade. Somente com laços assegurados na comunidade, o indivíduo seria realmente livre de um Estado totalitário. Depreende-se da obra de Nisbet o apelo a tradições que manteriam as associações humanas, como a ênfase no casamento e na participação religiosa como necessárias para se atingir a liberdade plena.

Em menos de cinco anos o conservadorismo norte-americano tomou forma com os trabalhos dos quatro autores supracitados. A partir de uma defesa da tradição e estabilidade; a "onda" intelectual conservadora dos anos 1950 rejeitava a modernidade científica tal como vivenciada e o coletivismo associado às políticas liberais de welfare. No entanto, restringiam-se a debates acadêmicos. Na década seguinte, com a divulgação da obra de Barry Goldwater (The Conscience of a Conservative) e a sua posterior candidatura a presidência norte-americana pelo Partido Republicano $^{10}$, o conservadorismo pode, então, vincular-se efetivamente a política e, como tal, expandir-se para fora das universidades e círculos intelectuais.

${ }^{10}$ Em 1960, quando escreveu The Conscience of a Conservative, Goldwater era Senador pelo Partido Republicano. Sua candidatura para a presidência pelo mesmo partido oficializou-se em 1964. 
O MOVIMENTO CONSERVADOR NORTE-AMERICANO DA DÉCADA DE 1950 E A PERCEPÇÃO CONSERVADORA A RESPEITO DA SOCIEDADE, ECONOMIA E POLITICA EXTERNA

Conceituando o conservadorismo como nothing more or less than an attempt to apply the wisdom and experience and the revealed truths of the past to the problems of today (GOLDWATER, 2009, p.3), o autor argumenta que: a) cada ser humano é constitudo de um lado imortal e um lado mortal; b) os aspectos econômicos e espirituais da natureza humana estão interligados; e c) o desenvolvimento do homem só é possível levando-se em conta os aspectos espirituais e materiais. Assim, cada ser humano é responsável por seu próprio desenvolvimento. A busca por desenvolvimento, no entanto, é condicionada a liberdade e a ordem.

Enfatizando a Constituição como um mecanismo de freio contra a tendência natural do governo de expansão em direção ao aboslutismo (Ibidem, p.10), o autor argumenta a necessidade de diminuição do tamanho do governo no que diz respeito as suas funções (tal como políticas de bem estar social) e as suas interferências na vida privada (tal como cobrança de impostos). Enfatiza ainda a necessidade de proteção dos valores e das tradições norte-americanas. Para isso, acredita que o governo deva ter como prioridade, ainda que com custos econômicos e sociais altos para a população, a vitória sobre o comunismo.

Associando-se a Nisbet, Goldwater também rejeita as políticas de welfare desempenhadas pelo governo; defedendendo, como solução, a transposição dessas políticas para o âmbito privado: indivíduos, igrejas, famílias, entre outros. Programas de bem estar social, cannot help but promote the idea that the government owes the benefits it confers on the individual, and that the individual is entitled, by right, to receive them (Ibidem, p.49). 0 governo deveria, em contrapartida, centralizar esforços para a proteção dos valores tradicionais norte-americanos baseados na religião, inclusive promovendo-os no país, e combater ameaças externas, tal como o comunismo.

A década de 1950 marca, assim, a ascenção do movimento conservador nos Estados Unidos, inicialmente restrito ao âmbito acadêmico e, a partir da candidatura de Goldwater na déca- 
da seguinte, já parte do Partido Republicano. Como princípios fundamentais, presentes na obra dos conservadores clássicos analisados, destacam-se: a busca por valores tradicionais norte-americanos; a ênfase na religião Cristã como propulsora da moralidade; a ênfase nas associações humanas - comunidade, família, igreja, entre outros; a aceitação da hierarquização e da desigualdade; a percepção do ser humano como possuidor de impulsos e apetites negativos; a rejeição a big governments; e a rejeição às políticas de bem estar social e de qualquer forma de nivelamento econômico ou social.

\section{Política Econômica: Percepção conservadora a respeito do tamanho do governo, de impostos e de políticas de bem estar social.}

A percepção conservadora sobre a economia pode ser considerada como a área que melhor representa o pensamento conservador clássico. A própria (re)emergência do conservadorismo norte-americano no período pós-guerra nasce como um descontentamento com a visão Keynesiana e de welfare $^{11}$ e é nessa área onde os princípios conservadores são mais homogêneos e representativos. Princípios típicos conservadores como defesa de um governo limitado, segurança para a propriedade privada e ênfase na liberdade econômica fazem parte dos trabalhos de todos os conservadores aqui estudados, recebendo uma ênfase relativamente maior do que as outras áreas, tais como política externa e questões sociais.

As políticas Keynesianas e de bem estar social desempenhadas pelo governo norte-americano no período pós-guerra são carac-

\footnotetext{
${ }^{11}$ A definição de Keynesianismo e de welfare é desenvolvida, mais claramente, por Buckley Jr. Para ele, ambas refletem políticas usadas por economistas que utilizam intervenções federais para solucionar problemas econômicos e, consequentemente, sociais (BUCKLEY JR., 2001, 1. 303).
} 
O MOVIMENTO CONSERVADOR NORTE-AMERICANO DA DÉCADA DE 1950 E A PERCEPÇÃO CONSERVADORA A RESPEITO DA SOCIEDADE, ECONOMIA E POLÍTICA EXTERNA

terizadas como uma "esquerdização" da economia (BUCKLEY JR., 2001, l. 201). Essa reorientação econômica, tal como percebida pelo governo norte-americano e no departamento de economia de Yale, usando-se de um pretexto humanitário, representaria a negação dos valores mais intrínsecos norte-americanos e que seriam responsáveis pela singularidade do país: ênfase na segurança da propriedade privada, liberdade econômica como livre iniciativa e individualismo (esse no sentido estritamente econômico, em contraposição ao coletivismo) ${ }^{12}$. 0 contrário disso seria o controle de produção, de regulação e de taxação, típicos do regime soviético. Assim, para os intelectuais conservadores clássicos, a utilização pelos Estados Unidos de preceitos econômicos, tais como os utilizados pelos soviéticos, seria uma violação dos princípios norte-americanos, esses mesmos princípios que os diferenciaria dos seus inimigos comunistas.

O governo limitado é um dos princípios básicos do conservadorismo e um dos que melhor o caracteriza em contraposição ao governo liberal - de bem estar social. Buckley Jr., Kirk, Nisbet, Weaver e Goldwater apontam para o que seria uma derivação lógica entre Keynesianismo (associado ao coletivismo) e totalitarismo. Segundo esses autores, na medida em que o governo toma para si as rédeas da economia, incentivando determinados setores em detrimento de outros, fixando preços, cobrando impostos desiguais e gradativos, e empregando indivíduos; ele se agiganta e, como consequência lógica, se torna um governo totalitário e despótico que seria responsável por destruir dois princípios importantes conservadores: a liberdade econômica e a segurança da propriedade privada.

0 governo agiganta-se e toma para si, progressivamente, o que antes era desempenhado por indivíduos e por associações, como

\footnotetext{
${ }^{12}$ De acordo com Buckley Jr., os professores de Yale estariam ensinando seus alunos a procurarem segurança (trabalho para o governo) ao invés de enterprise: And Dean DeVane was astounded, puzzled and shocked in 1949 when he read that the graduating class seemed more interested in security that in enterprise. [...] Individualism is dying at Yale, and without a fight (BUCKLEY JR., 2001, l. 1824-2146).
} 
por exemplo, o welfare, antes domínio da igreja; restringindo, assim, a liberdade individual e das associações comunitárias (NISBET, 2010). 0 governo totalitário, vestindo a máscara de virtuoso ao impor um modelo igualitário e, consequentemente justo; invade por completo a privacidade humana e impõe um nivelamento não só artificial, mas irracional e injusto. Situação só possível, no entanto, quando todos os contextos sociais de privacidade (família, igrejas, etc.) forem enfraquecidos:

Such a state may well call itself democratic and humanitarian. All contemporary totalitarian states so refer to themselves. Such a state may found itself upon the highest principle of virtue, even as did the republic of Plato. There can be such a thing as democratic totalitarianism even as there can be, as we have learned in disillusion, socialist totalitarianism. [...] The impersonal despotism of virtue, as someone has said, is not the less despotic because it is virtuous (Ibidem, l. 4704).

Nesse sentido, é importante enfatizar que o conservadorismo prega tanto a liberdade, como a responsabilidade individual que dela advém. Da mesma maneira que não se pode interferir no desenvolvimento do caminhar de uma criança (ainda que ela caminhe, quando a ajuda for retirada, ela ira cair novamente, só caminhando quando o seu corpo estiver pronto para essa tarefa), também não se pode interferir no desenvolvimento econômico dos indivíduos: Man's development is in both spiritual and material aspects and is not something that can be directed by ouside forces. Each one is responsible for his own development (GOLDWATER, 2009, p.7). 0 governo que o faz, ainda que com objetivos "humanitários", não só restringe a liberdade individual e atrasa o desenvolvimento intrínseco e necessário de cada indivíduo, já que tudo providencia aos seus "súditos"; como também, se engrandece cada vez mais ao exigir conformidade rígida em troca do seu papel "paterno". Nessa situação, os indivíduos se mantêm em condição de eternas crianças. 0 estado de bem estar social, portanto, assemelha-se, em última instância, aos go- 
O MOVIMENTO CONSERVADOR NORTE-AMERICANO DA DÉCADA DE 1950 E A PERCEPÇÃO CONSERVADORA A RESPEITO DA SOCIEDADE, ECONOMIA E POLÍTICA EXTERNA

vernos totalitários nazistas e comunistas: em todos os três tipos o governo é exercido do topo para baixo (KIRK, 1953, p.182). Assim, os conservadores clássicos enfatizam a necessidade de manter o governo o menor possível com relação a suas atribuições, responsável apenas por manter a segurança dos indivíduos e, consequentemente, da propriedade privada; e por impor normas morais sociais de acordo com a tradição Cristã: ordem, hierarquia, justiça e liberdade.

Para o conservador clássico, a liberdade está fortemente vinculada à propriedade já que, ao separar a propriedade do direito à posse privada, a liberdade é corrompida (KIRK, 1953, p.8). Por liberdade entende-se o propósito e o processo pela qual o indivíduo é considerado senhor da sua própria vida (KIRK, 2002, l. 810). A política de interferência econômica, portanto, ao propor impostos gradativos e controle de produção, por exemplo, fere o indivíduo no que ele possui de mais intrínseco: a decisão de como controlar sua própria vida e, como tal, fere ao mesmo tempo dois dos princípios supremos conservadores: a liberdade e a propriedade privada. Dessa maneira, propriedade e liberdade são inseparáveis: no momento em que o governo entra em uma esfera (através da cobrança de impostos, por exemplo), está, automaticamente, adentrando na outra (GOLDWATER, 2009, p.40).

A redistribuição econômica através da taxação mais alta para indivíduos mais ricos e a transferência direta, ou indireta (através de serviços gratuitos ou subsidiados pelo governo,) para os grupos de baixa renda tal como advogavam o governo liberal norte-americano no pós-guerra; seria uma tentativa de buscar "justiça" econômica e social. Essa noção, no entanto, é refutada pelos conservadores clássicos. Ao contrário de ser justa, essa política seria uma negação do princípio de justiça, tal como entendido pelos conservadores. 0 imposto gradativo seria um confisco arbitrário, utilizado por um grupo para impor uma noção de social welfare tal como definida e entendida por esse mesmo grupo, ou seja, uma noção igualitária (Ibidem, l. 1535) baseada em "direitos naturais" (KIRK, 1953, p. 42). 
É pertinente ressaltar a noção de justiça e de igualdade, tal como percebida pelos conservadores. Por justiça entende-se "merecimento", ou seja, que cada um receba o que merece de acordo com seus próprios méritos, talentos e esforços: To each, his own (KIRK, 2002, l. 797). Políticas de welfare, baseadas na redistribuição seria uma injustiça, ao retirar de quem o fez por merecer para distribuir para quem não o fez. Um governo justo, ao contrário, will endeavor to ensure that no one shall take from another man what properly belongs to his personality, his station in life, and his material interests (Ibidem, l.844). Para Weaver (2008), políticas de redistribuição e nivelamento econômico são análogas ao que o autor sugere como a "psicologia da criança malcriada": À criança malcriada não lhe foi ensinado a compreensão de que se possa existir uma relação entre esforço e recompensa (Ibidem, l. 1390); assim, se mantém a crença de que o progresso material e moral é alcançado de maneira automática, sem esforço ou dedicação. Recebendo auxílio econômico de um governo "bem feitor", os indivíduos se mantêm como eternas crianças malcriadas, sendo também os seus súditos mais servis.

Por igualdade, entende-se a igualdade perante a lei e perante Deus (igualdade moral) ${ }^{13}$. Qualquer outra igualdade não é reconhecida pelos conservadores. De acordo com um dos seis cânones conservadores defendidos por Kirk (1953), uma sociedade civilizada necessita de ordem e de classes, sendo a moralidade a única igualdade aceita - todas as outras "igualdades" seriam artificiais (Ibidem, p.8). 0 conservadorismo se caracteriza justamente pela negação da igualdade (a não ser pelo caso supracitado). Todo o pensamento conservador está envolto em noções de ordem, hierarquia e classes. A uniformidade seria uma tentativa artificial que contraria as diferenças naturais e necessárias para uma sociedade que busca a "ordem, a justiça e a liberdade"; longe de ser "natural" ou "justa", a igualdade econômica ou social

${ }^{13}$ Para Kirk, o conservadorismo caracteriza-se pela convicção de que os homens são iguais somente aos olhos de Deus, não mais que isso (KIRIK, 1953, p.15). 
O MOVIMENTO CONSERVADOR NORTE-AMERICANO DA DÉCADA DE 1950 E A PERCEPÇÃO CONSERVADORA A RESPEITO DA SOCIEDADE, ECONOMIA E POLÍTICA EXTERNA

é artificial e injusta: Equality is the product of art, not of nature; and if social leveling is carried so far as to obliterate order and class, art will have been employed to deface God's design for man's real nature (Ibidem, p.52).

Por fim, a noção de "direito natural", tal como desempenhada pelos igualitários e defensores do estado de bem estar social, seria uma tentativa errônea de caracterização de direitos, confundindo "direitos" com “desejos" (Ibidem, p.42; WEAVER, 2008 l. 204). 0 único direito natural do ser humano é caracterizado como condição e ação humana em conformidade com a lei divina (KIRK, 1953, p.44). Se os direitos são, portanto, confundidos com aspirações, os indivíduos perdem a noção de merecimento e, principalmente, perdem a referência da lei divina. Para Kirk, Equal justice is indeed a natural right; but equal dividend is no right at all. The laws of nature, ordained by Divine wisdom make no provision for sharing goods without regard for individual energies (Ibidem, p.48).

A política redistributiva seria uma noção contrária a sabedoria divina, princípio que rege o pensamento conservador ${ }^{14}$. A desigualdade e a diferença faria parte do plano divino. Deus fez os indivíduos diferentes em todos os sentidos (intelectual, físico, emocional, etc.) para assim passarem pelos percalços e sofrimentos da vida antes de obter a redenção espiritual futura ${ }^{15}$. De acordo com Kirk (1953), o propósito de todo indivíduo não é a indulgencia de apetites e aspirações, mas a obediência à ordem divina. Ainda que não compreendidas em sua totalidade, as dificuldades e as diferenças intrínsecas entre os indivíduos fazem parte do plano divino, devendo ser seguidas (KIRK, 1953, p.28)

\footnotetext{
${ }^{14} 0$ primeiro cânone conservador tal como defendido por Kirk (1953, p.7) refere-se à crença de que um propósito divino ordena a sociedade.

${ }^{15}$ Christianity envisages a framework for human society in which earthly miseries have a recognized, permanent, and honorable place. They are trials sent by Heaven to test and train us; as such, it is impious to repine against them (KIRK, 1953, p.31).
} 
Dessa maneira, impor uma igualdade artificial através de políticas de redistribuição baseadas em um governo de bem estar social seria tanto uma injustiça (com relação à noção de merecimento) como uma negação dos princípios divinos de diferenciação e de progresso espiritual. A negação da autoridade de Deus, tal como os conservadores clássicos a percebem na tentativa do governo de bem estar social, promoveria o totalitarismo na medida em que o governo acumula funções não antes designadas, mas principalmente porque, ao negar a autoridade mais importante (Deus), nega também outras autoridades institucionais, tal como família e igreja, responsáveis pelo contrapeso a tentativas despóticas e totalitárias de governos (BUCKLEY JR., 2001, l. 114-126).

Por fim, o estado de bem estar social e a redistribuição baseada em impostos gradativos corromperia o progresso moral e material da sociedade na medida em que esse só é possível com graus de desigualdade presentes. Sendo os indivíduos naturalmente diferentes entre si, inclusive com relação à inteligência, esforço, perseverança, e oportunidades; a única forma de se progredir, materialmente ou moralmente, seria se inserido em um ambiente caracterizado por desigualdade natural. Um indivíduo só irá buscar progredir se lhe é dado esse direito, ou seja, se ele é livre para poder colher os frutos do seu próprio progresso e desenvolvimento sem a interferência do governo, como por exemplo, no setor fiscal. No momento em que há a ameaça de um nivelamento econômico e, portanto, um confisco fiscal sobre a propriedade privada de um indivíduo que poderia progredir materialmente por esforço e dedicação próprios, esse mesmo indivíduo optará por não realizar todo o esforço que então despenderia, já que não irá obter os frutos advindos do seu progresso: It is indeed, this inequality of condition between the front and rear ranks, in the march of progress, which gives so strong an impulse to the former to maintain their position, and to the latter to press forward into their files (KIRK, 1953, p.156)

Assim, o conservador clássico se impõe como opositor de qualquer política que possa aumentar as atividades do governo, tais 
O MOVIMENTO CONSERVADOR NORTE-AMERICANO DA DÉCADA DE 1950 E A PERCEPÇÃO CONSERVADORA A RESPEITO DA SOCIEDADE, ECONOMIA E POLÍTICA EXTERNA

como a taxação gradativa para a promoção de um estado de welfare, sob risco de agigantá-lo a ponto de torná-lo um governo totalitário e, consequentemente, indiferente à liberdade individual. De fato, um governo que interfere em setores tidos como privados pelos conservadores para buscar um nivelamento econômico e social, típico de um estado de bem estar social; contraria todos os princípios mais importantes conservadores de obediência ao plano divino (ordem, hierarquia e justiça), liberdade individual e respeito à propriedade privada. A taxação gradativa e as políticas de interferência econômica, além de agigantar um governo que deve ser mínimo, mutilariam a sociedade de vigor e esperança, restringindo, assim, o desenvolvimento moral e material dos indivíduos que dela fazem parte.

\section{POLÍTICA EXTERNA: Percepção conservadora sobre o inimigo externo, Israel e multilateralismo e imperialismo.}

A emergência do conservadorismo na década de 1950 buscava, no intuito de conter o caos e a dissolução do Ocidente, o combate ativo ao comunismo como política e o socialismo como economia. Da mesma maneira que a política econômica era vista como corrompida por conta de valores de coletivismo, também a política externa desempenhada no período pós-guerra (apaziguamento) era, para os conservadores, uma corrupção dos valores norte-americanos. Efetivamente, o comunismo refletia o contrário de todos os valores tidos como sagrados pelos conservadores: liberdade, religião, hierarquia, diversidade e governo mínimo. A rejeição conservadora à política de governo da União Soviética, portanto, fica óbvia. 0 objetivo do estudo aqui proposto, no entanto, não é uma análise focada estritamente no anticomunismo típico conservador, haja vista que seria difícil analisar as plataformas e políticas republicanas recentes com base específica na rejeição ao comunismo. Assim, se busca, ainda que se utilizando da retórica anticomunista presente nos trabalhos dos autores 
aqui estudados, uma análise mais ampla sobre a percepção dos mesmos com relação a inimigos externos, a Israel e a dicotomia caracterizado pelo multilateralismo versus imperialismo.

A caracterização da área de política externa, conforme é percebida pelos conservadores, impõe certas dificuldades em função de ser essa uma área bastante ambígua. Ao contrário das áreas de política econômica e questões sociais, onde alguns princípios conservadores são bastante claros (por exemplo, a ênfase na não interferência do governo na propriedade privada e a rejeição ao aborto), a posição dos Estados Unidos, de acordo com o conservadorismo, não deve ser nem isolacionista, nem intervencionista; não deve intervir para impor um modelo de democracia tal qual o modelo norte-americano, mas deve intervir para instaurar a liberdade; não deve entrar em guerras por questões materiais, mas por questões de interesse nacional. Ou seja, em todos os casos, uma linha tênue separa o que é permitido, do que não o é. Assim, para entender a lógica conservadora referente à política externa, é importante mencionar alguns princípios básicos conservadores: defesa do seu país e das tradições; prudência; tolerância e pluralidade; e crença nos valores cristãos.

A ênfase na defesa do seu país é uma derivação da ênfase conservadora na promoção da defesa contínua do seu lar, sua família, sua comunidade. Assim como a casa de um conservador é, para ele, o seu castelo, também o é a comunidade que faz parte, em última análise, o seu país. Buckley Jr. (2001), Nisbet (2010) e Goldwater (2009) são bastante enfáticos ao relacionar moralidade e patriotismo, bem como direitos e deveres. Entende-se que é um dever moral do cidadão norte-americano lutar pela defesa do seu país, tal como defenderia a sua família. Da mesma maneira, a noção conservadora de responsabilidade, ou seja, de que com cada direito carrega-se junto um dever; supõe que um cidadão dos Estados Unidos, que tem o direito aos princípios morais mais elevados e base da sociedade norte-americana - ordem, justiça e liberdade (KIRK, 1953) - também tem o de- 
O MOVIMENTO CONSERVADOR NORTE-AMERICANO DA DÉCADA DE 1950 E A PERCEPÇÃO CONSERVADORA A RESPEITO DA SOCIEDADE, ECONOMIA E POLITICA EXTERNA

ver de preservá-los. Acreditando ser a Guerra Fria uma batalha contra um adversário que corromperia os valores, tradições e, consequentemente, o próprio país; seria imoral não defendê-lo veementemente.

0 princípio da prudência, no entanto, também deve ser levado em conta. Esse princípio, mais visível nos trabalhos de Kirk (1953) e Nisbet (2003 e 2010), propõe uma certa desconfiança às soluções rápidas e imediatas, buscando sempre analisar o todo e de maneira pragmática para não incorrer em erros de cálculo, difíceis de serem revertidos posteriormente. A prudência aconselha a agir somente depois de pesados os custos e os benefícios prováveis, onde os benefícios são maiores e suficientes para cobrir os possíveis custos dispensados. Nesse sentido, dois outros princípios - a presença do evil e a humildade - explicam, também, a busca pela prudência. 0 conservador tem consciência de que o inimigo representa um perigo e de que erros de cálculo e de percepções são comuns, haja vista que o ser humano é um ser imperfeito. Além do mais, o conservador sabe ainda que os custos, tanto de intervenções como de combates externos, são muito altos: agiganta o governo, aumenta os impostos pagos pelo cidadão e rompe o status quo.

Um terceiro princípio importante para a compreensão da política externa conservadora é a aceitação da tolerância e da pluralidade. Segundo Kirk (1953), os conservadores se caracterizam por uma afeição pela variedade da vida tradicional, ao contrário da uniformidade e igualdade dos sistemas mais radicais (Ibidem, p.8). A diferença, sendo uma característica natural e, portanto, divina, é apreciada tanto nas relações entre seres humanos, quanto entre países. Para os conservadores, essa diferença, no entanto, não deve ameaçar nem a liberdade individual, nem a nacional.

Por fim, a crença nos valores cristãos norte-americanos - e morais - de ordem, justiça e liberdade, devem ser mantidas e preservadas como bens supremos. A existência e o progresso humano 
dependem, na visão conservadora, da manutenção desses princípios. Qualquer ameaça a eles, como foi entendida a ameaça comunista, significa, também, que deve ser rechaçada sob risco de decadência moral, espiritual e material. A partir do entendimento desses princípios, a política externa, tal como defendida pelos intelectuais clássicos, passa a ser mais clara e menos ambígua.

Primeiramente, é interessante analisar a posição conservadora com relação a Israel. Os conservadores são associados, frequentemente, à leniência e à proteção a esse país. De fato, os autores aqui analisados enfatizam as raízes judaico-cristãs dos Estados Unidos e, como tal, responsável pela moralidade norte-americana. Kirk, em especial, dedica boa parte de uma obra sua sobre a linhagem judaico-cristã e que seria responsável pela "ordem" norte-americana ${ }^{16}$. Segundo esse autor, a história da fé cristã, a noção de ordem baseada em Deus e as próprias raízes norte-americanas têm origem em Israel: American moral order could not have come into existence at all, had it not been for the legacy left by Israel (KIRK, 2003, 1. 595). Ambos os países possuem, de acordo com Kirk, uma origem e literatura cristã comuns, além de experiências históricas similares, o que explicaria, portanto, a relação amigável entre os dois. De certa forma, uma ameaça estrangeira a Israel seria, também, uma ameaça aos EUA, haja vista que seus valores são tão intrínsecos e similares. A essa visão, no entanto, alia-se os outros princípios conservadores, tal como a prudência. A proteção a Israel não é, portanto, fixa. Da mesma maneira que o conservadorismo rejeita a intervenção e o combate externo a não ser em casos onde os interesses norte-americanos são efetivamente ameaçados, também rejeita a proteção a Israel caso os valores judeus não estiverem em risco.

Com relação ao inimigo externo, nota-se uma preocupação conservadora tão somente no que diz respeito à segurança dos

\footnotetext{
${ }^{16}$ Nessa obra, o conceito de "ordem" é definido como o caminho que se segue, ou se vive, com um propósito e significado (KIRK, 2003, l. 369)
} 
O MOVIMENTO CONSERVADOR NORTE-AMERICANO DA DÉCADA DE 1950 E A PERCEPÇÃO CONSERVADORA A RESPEITO DA SOCIEDADE, ECONOMIA E POLITICA EXTERNA

princípios norte-americanos; ou seja, um inimigo externo não precisa, necessariamente, ser combatido se ele não ameaçar a segurança desses valores e, consequentemente, da própria existência dos Estados Unidos como nação. O conservadorismo, segundo Buckley Jr. (2001), Goldwater (2009), Nisbet (2003 e 2010) e Kirk (1953 e 2002); acredita que só se deve entrar em conflito com um inimigo externo quando para defesa ante uma ameaça a seus interesses e princípios nacionais. 0 conservadorismo não gosta de guerra (NISBET, 2010). Um conflito armado significa agigantamento do governo e maiores impostos pagos pelo cidadão. Ele se torna possível, no entanto, no momento em que as comunidades locais foram enfraquecidas. Para ele, guerras produzem um warming sense of community (Ibidem, l. 1078). Assim, o que antes se buscava na família, igreja e associações (um sentido de pertencimento, de identificação com os outros), se procura, então, na luta comum contra um inimigo externo. The enemy becomes not only a ready scapegoat for all ordinary dislikes and frustrations; he becomes the symbol of total evil against which the forces of good may mobilize themselves into a militant community (Ibidem, l. 1021).

Contudo, ainda que os conservadores não gostem de guerras por conta das consequências que essa produz na liberdade dos indivíduos; nos casos em que os valores e a existência norte-americana são ameaçados, a guerra deixa de ser uma opção para se tornar uma obrigação. Tanto Buckley Jr. (2001) como Goldwater (2009) enfatizam a imoralidade e a tragédia da política de apaziguamento com um inimigo externo que, como no caso da União Soviética tal como entendido pelos conservadores, ameaça tanto os valores norte-americanos sociais, políticos, econômicos e morais, como também a própria existência do Estado como tal. O conservadorismo está relacionado com comprometimento. Comprometimento com a família, com a comunidade e, em última instância, com o país. A política de apaziguamento, portanto, é completamente rejeitada pelo conservadorismo quando o inimigo externo ameaça efetivamente os valores norte-americanos. 
Para Goldwater (2009), ainda que a guerra seja a pior das opções, em alguns casos, ela é a única (GOLDWATER, 2009, p.75).

Por fim, a concepção conservadora a respeito do multilateralismo e imperialismo deve ser analisada sob o prisma do pragmatismo. Os conservadores da geração de 1950 defendem o princípio de não intervenção. Na percepção conservadora, o Estado intervencionista se torna, invariavelmente, um estado totalitário e imprudente que buscaria a uniformidade global ao invés da pluralidade e cujos custos (políticos e econômicos) são pagos pelo cidadão. Pode-se, ainda, entender a relutância conservadora em intervenções externas por conta da percepção desses a respeito do progresso e da responsabilidade individual. Assim como as pessoas devem buscar desenvolverem-se sozinhas, portanto sem ajuda federal econômica sob risco de permanecerem eternamente crianças (WEAVER, 2008), também os estados devem alcançar seu progresso de maneira própria, sem ajuda externa. Além disso, por conta dos princípios da prudência, e do reconhecimento do pluralismo e da imperfeição humana, os conservadores têm receio de políticas externas intervencionistas que buscam instaurar governos ao seu molde. Kirk (1953) argumenta, por exemplo, que não existe um único estilo de governo "certo" para todos os países do mundo, assim como não existe uma única religião ou profissão para todos indivíduos. Cada país deve escolher o seu tipo de governo ideal de acordo com a sua história, seus costumes, crenças e cultura; desde que não ameace os interesses e valores norte-americanos. De fato, essa é a linha que define quando se deve intervir e quando se deve abdicar da intervenção: enquanto os valores dos cidadãos norte-americanos e a existência da nação como tal não forem ameaçados, a prudência na decisão de intervir é a melhor solução; no entanto, caso haja uma ameaça efetiva, a intervenção deve ser feita ${ }^{17}$.

${ }^{17}$ De acordo com Nisbet (2003), a política de neutralidade antes da segunda Guerra Mundial foi uma boa estratégia, assim como o foi a intervenção posterior ao ataque de Pearl Harbor. 
O MOVIMENTO CONSERVADOR NORTE-AMERICANO DA DÉCADA DE 1950 E A PERCEPÇÃO CONSERVADORA A RESPEITO DA SOCIEDADE, ECONOMIA E POLÍTICA EXTERNA

O multilateralismo deve ser entendido da mesma forma pragmática que o intervencionismo: enquanto o multilateralismo (sistema de alianças, ajuda externa, negociações e organismos multilaterais) for benéfico aos interesses norte-americanos, deve ser mantido; quando não o for, deve ser recusado em prol da soberania norte-americana. 0 conservadorismo tem a preocupação de analisar o todo - assim o faz quando busca analisar não só os "direitos" dos homens, mas também da família, da comunidade e do país. 0 conservador clássico, portanto, entende que é mais difícil conseguir alguma vitória no plano internacional sem ajuda de outros países; da mesma forma que é mais difícil para um indivíduo, sozinho, obter uma vitória sobre o governo federal - tendo mais força de persuasão se inserido em uma comunidade. Dessa maneira, sempre que possível, o conservador busca no multilateralismo a força necessária para proteção dos seus interesses.

Contudo, os conservadores clássicos e, em especial, Goldwater, argumentam que nem sempre o multilateralismo fortalece os interesses norte-americanos, sendo responsável, às vezes, pelo seu enfraquecimento. 0 sistema de alianças, por exemplo, pode ser prejudicial se mantém a política de apaziguamento quando os valores e a segurança norte-americana estão em perigo (GOLDWATER, 2009, p.63). O pragmatismo também deve ser levado em conta com relação à ajuda externa, inclusive nas Nações Unidas. Filantropia global, sem recompensa em termos de interesses nacionais ou objetivos políticos e estratégicos, não é pragmático. Os custos econômicos devem reverter positivamente para compensar o confisco na forma de impostos.

Enfim, entende-se que a posição conservadora, por conta de princípios como a prudência, a ênfase na liberdade, na pluralidade e nos valores tradicionais cristãos; possui uma preocupação especial com Israel, formando com esse país uma aliança por conta de valores comuns; preferem o multilateralismo e a não intervenção externa quando essas opções são possíveis e não ameaçam os interesses norte-americanos; e, por fim, admitem 
a possibilidade de um conflito com um inimigo externo apenas como uma última possibilidade. Nesse sentido, a afirmação de Goldwater resume o pensamento conservador a esse respeito: I would remind you that extremism in the defense of liberty is no vice. And let me remind you also that moderation in the pursuit of justice is no virtue (GOLDWATER, 1964). 0 conservadorismo, assim, pode ser considerado como um "intervencionista moderado", baseando suas decisões no pragmatismo de acordo com uma perspectiva de interesse nacional e, não, global

5. Questões sociais: Percepção conservadora sobre imigração, aborto e família.

O terceiro pilar que sustenta o conservadorismo clássico refere-se ao descontentamento com o rumo tomado pela sociedade norte-americana. Políticas liberais baseadas em noções de "direitos humanos"; a ênfase no progresso humano por conta do racionalismo científico; e o enfraquecimento das tradições, comunidades e do papel da igreja seriam os responsáveis por uma sociedade corrompida, incapaz de discernir valores, hierarquia e ordem (WEAVER, 2008, l. 239). 0 governo liberal, de acordo com os conservadores estudados, significava o enfraquecimento das comunidades, a desintegração social e a alienação dos indivíduos - alienação com relação a Deus, família, igreja e entre si. Assim, the new individual is in a spiritual and moral void (NISBET, 2010, l. 672). As políticas liberais desempenhadas pelo governo norte-americano, nesse sentido, seriam responsáveis por essa alienação na medida em que enfraquece as comunidades e as associações e, com isso, enfraquece também as tradições e valores arraigados a elas.

A percepção conservadora a respeito da imigração, família e aborto deve ser entendida levando-se em conta, também, outros princípios já analisados: a ênfase na religião e na crença de que a fé em Deus e aderência rígida aos preceitos Cristãos são as for- 
O MOVIMENTO CONSERVADOR NORTE-AMERICANO DA DÉCADA DE 1950 E A PERCEPÇÃO CONSERVADORA A RESPEITO DA SOCIEDADE, ECONOMIA E POLITICA EXTERNA

ças mais poderosas para uma vida moral e justa; a obediência a lei divina e as obrigações que essa traz consigo; a noção de responsabilidade individual; e a ênfase na tradição e nas instituições tradicionais.

A importância da instituição familiar é, para os conservadores, evidente em si mesma: A família, a comunidade local e a igreja desempenhariam um papel fundamental para a manutenção da ordem e da moralidade já que seriam as responsáveis pela condução dos indivíduos a determinadas regras de conduta e de crenças que, por sua vez, seriam responsáveis pela moralidade norte-americana (NISBET, 2010, l. 790). Essas instituições, além de promoverem a autoridade e a hierarquia necessárias para a condução da ordem e da moralidade, também desempenhariam um papel de proteção às liberdades individuais já que mantém o governo limitado.

Para os conservadores, a instituição familiar estaria sendo enfraquecida por políticas liberais, por novas autoridades e por uma noção de imediatez que culminaria, assim, na desestruturação da família (WEAVER, 2008). Os casamentos ${ }^{18}$, antes reconhecidos como um elo sagrado e necessário à moralidade da sociedade, estariam sendo desfeitos por conta do sentimento de imediatez e de uma suposta autossuficiência e autorealização (NISBET, 2010). A ruptura de casamentos e, como consequência, o enfraquecimento da família moderna; seria uma erosão de sua autoridade e de funções que antes eram desempenhada por ela mas que passam a ser desempenhadas, progressivamente, pelo Estado $^{19}$. A família, antes o espinha dorsal da sociedade, se transformava em um acidente para o trabalhador, ao invés de sua essência (Ibidem, l.1328). Assim, os conservadores argumentam a

\footnotetext{
${ }^{18} \mathrm{O}$ casamento é entendido como a união entre um homem e uma mulher cuja responsabilidade é de child care (BUCKLEY JR., 2006a)

${ }^{19}$ Para Buckley Jr. (2000, p.22), a única coisa que o liberal moderno está intressado é em liberar o homem do seu casamento.
} 
necessidade de fortalecer a família no sentido de retransmitir a ela a significância moral e psicologica de antes.

A posição conservadora referente ao aborto deve ser analisada tendo em mente a ênfase na defesa da família, na moralidade e na obediência às leis divinas; a noção de responsabilidade; e, por fim, o respeito à Constituição. 0 aborto é entendido como uma ação contra a vontade divina. A concepção de uma criança é, no entendimento conservador, uma vontade de Deus e, como tal, é ímpio descontentar-se. Tirar a vida de um ser criado por Deus e, portanto, parte de uma sabedoria divina, seria não só contrário aos preceitos cristãos, mas também imoral. De acordo com Buckley Jr. (2007, p.172), a questão acerca da existência ou não de vida antes do nascimento é uma questão biológica com implicações morais. Assim, qualquer método que venha a interromper propositalmente o desenvolvimento de uma criança seria imoral.

Weaver atenta para o egoísmo típico do liberal moderno que, ao alienar-se das suas tradições e instituições, aliena-se, também, de outros indivíduos e da responsabilidade que lhe seria outorgada por esses: Seu desejo já é motivo suficiente (WEAVER, 2008, l. 868). Para ele, a piedade e o senso de justiça são corrompidos em função de um egoísmo típico que se manifesta quando o indivíduo alcança um estado em que já não é mais capaz de aceitar que as coisas não criadas ou desejadas por ele tenham o direito de existir (Ibidem, l. 2089). Nesse sentido, a prática do aborto poderia ser considerada um exemplo típico tanto de alienação; quanto de egoísmo, já que corrompe as noções tradicionais conservadoras de responsabilidade e de justiça.

Por fim, a rejeição ao aborto pelos conservadores pode ser entendida como uma interferência judicial alheia a Constituição e, como tal, inconstitucional. De acordo com Kirk (1987), as decisões da Suprema Corte norte-americana, tal como a legalização do aborto (Roe v. Wade, 1973), são baseadas em judges hearts' 
O MOVIMENTO CONSERVADOR NORTE-AMERICANO DA DÉCADA DE 1950 E A PERCEPÇÃO CONSERVADORA A RESPEITO DA SOCIEDADE, ECONOMIA E POLITICA EXTERNA

desires que altera a Constituição de acordo com a vontade de alguns indivíduos: uma aristocracia jurídica ou conselho de anciãos, the Ephors of Washington (Ibidem).

Finalmente, referente à imigração, os conservadores entendem que as suas tradições e a própria constituição do seu Estado são heranças de imigrantes. No entanto, um número alto de imigrantes traz, obviamente, consequências econômicas para o governo que serão retransmitidas ao cidadão na cobrança de maiores impostos. Além disso, em números muito elevados, os imigrantes ameaçam a comunidade típica, a tradição e os valores norte-americanos, já que carregam com eles uma herança cultural que difere da norte-americana. Assim, a preocupação de Nisbet com relação a qualquer política ou grupo que ameace as instituições tradicionais, bem como as tradições culturais e religiosas que delas advêm; pode ser transplantada para a preocupação conservadora referente à imigração e aos imigrantes ilegais. Da mesma forma, Buckley sugere uma maior ênfase na assimilação de imigrante já legalizados ao American way of life cujo primeiro passo seria fazer do inglês a língua obrigatória (BUCKLEY JR, 2006 b). A perda da supremacia da língua (como já ocorre em diversas regiões do país), é, para os conservadores, indício de perda da supremacia norte-americana em outros níveis também: perda dos valores morais, da tradição e dos princípios norte-americanos. A questão da imigração, portanto, demonstra-se um assunto sensível.

\section{Considerações finais}

0 conservadorismo norte-americano que surge na década de 1950 e traduz-se em um movimento relativamente homogêneo é perceptível inicialmente através das obras de autores que tiveram papel fundamental para dar a ele a sua forma. Uma vez estabelecido no meio intelectual por conta desses autores, o conservadorismo passa a ser usado por determinas lideranças políticas, como é o caso de Goldwater na década de 1960. 0 
conservadorismo clássico, no entanto, não deve ser entendido a parte do contexto histórico em que surge.

0 movimento conservador que surge na década de 1950 é, antes de tudo, uma rejeição ao que se vivenciava no momento e ao rumo que os Estados Unidos, aparentemente, tomavam. Duas guerras mundiais, armas nucleares, a grande depressão de 1929 e Comunismo marcavam o período imediatamente anterior a emergência do conservadorismo norte-americano. Somando-se a isso, a corrupção na política norte-americana (cada vez mais associada aos bosses e a grupos de interesse), o aumento de crimes nas regiões metropolitanas e o fortalecimento do New Deal são percebidos por um grupo de indivíduos (dentre eles os autores conservadores) como evidências de uma desintegração moral que pode ser refletida em todas as áreas - política, economia e sociedade, bem como em todos os âmbitos - do local ao global.

Governos totalitários e, em especial, o comunismo presente na União Soviética passa a ser a personificação dessa desintegração moral: governo totalitário e socialista cujos líderes buscavam se distanciar da religião. 0 conservadorismo que surge nesse momento, portanto, é a antítese do comunismo. É a busca por uma valores e políticas completamente contrárias ao "liberalismo" que ascendia nos Estados Unidos desde a era Progressista e que, nesse momento, passa a ser associado ao comunismo. Na área econômica, rejeita o New Deal e enfatiza aspectos libertários como a defesa a propriedade privada e a diminuição do tamanho do governo. Na política externa, é contrário à política de apaziguamento com a União Soviética, enfatizando uma ampla defesa da nação sob um viés pragmático contra países e regimes que, como no caso da União Soviética, "ameaçam" a soberania e os valores norte-americanos. Por fim, no âmbito social, rejeita o secularismo e o ateismo defendendo, ao contrário, a retomada de valores e tradições Cristãs. 0 movimento conservador que se dá a partir de 1950 nos Estados Unidos, portanto, busca opor-se à tendência liberal que se projetava nesse país, servindo como um freio à noções tipicamente progressistas. 
O MOVIMENTO CONSERVADOR NORTE-AMERICANO DA DÉCADA DE 1950 E A PERCEPÇÃO CONSERVADORA A RESPEITO DA SOCIEDADE, ECONOMIA E POLÍTICA EXTERNA

\section{Referências Bibliográficas}

ANSELL, Amy (ed). Unraveling the Right: The new conservatism in American thought and politics. Boulder: Westview Press, 2001.

BREWER, Mark D. e STONECASH, Jeffrey M. Dynamics of American Political Parties. New York: Cambridge University Press, 2009.

BUCKLEY JR., William F. Nearer, My God: An Autobiography of Faith. New York: Doubleday, 1997.

. Let Us Talk of Many Things: The Collected Speeches. New York: Basic Books, 2000.

. God and Man at Yale. Washington: Regnery Publishing; Kindle ebook, 2001.

. Gay Impasse. National Review Online. Outubro 2006(a). Disponivel em: <http://www.nationalreview.com/articles/219076/gay-impasse/ william-f-buckley-jr> Acesso em 20/11/2012.

. Illegal Conundrums. National Review Online. Abril 2006(b). Dis-

ponivel em: <http://www.nationalreview.com/articles/217302/illegal-conundrums/william-f-buckley-jr $>$ Acesso em 20/11/2012.

Cancel Your Own Goddam Subscription: Notes and Asides from National Review. New York: Basic Books, 2007.

COOPER, Michael: Platform's sharp turn to right has Republicans cheering. The New York Times - 28/08/2012. Disponivel em: http://www.nytimes. com/2012/08/29/us/politics/republican-platform-takes-turn-to-right. html? r=1\&ref=politics Acesso em 30/08/2012.

EDWARDS, Mickey. Reclaiming Conservatism. Oxford: Oxford University Press, 2008.

FIORINA, Morris, P. What Happened to the Medium Voter? MIT Conference on Parties and Congress, 1999. Disponível em: <http://www.stanford.edu/ mfiorina/ Fiorina\%20Web\%20Files/MedianVoterPaper.pdf> Acesso em 12/1/2013.

. Culture War? The Myth of a Polarized America. New York: Pierson Longman. 2005.

FIORINA, Morris, P. e ABRAMS, Samuel J. Political Polarization in the American Public. Annual Review of Political Science. 2008. Disponível em: <http:// www.acsu.buffalo.edu/ jcampbel/documents/AnnualReviewFiorina.pdf> Acesso em 4/8/2012. 
GOLDWATER, Barry. Speech accepting the Republican Presidential Nomination. San Francisco. 16 de Julho de 1964. Disponivel em: http://www. americanrhetoric.com/speeches/barrygoldwater1964rnc.htm (acessado em 12/10/2012). book. 2009.

The Conscience of a Conservative. Qualiteri Publishing; Kindle e-

G.O.P. Republican National Platforms. Disponivel em $<$ http://www.presidency. ucsb.edu/platforms.php> Acesso em: 21/05/2012.

GOTTFRIED, Paul. Conservatism in America: Making sense of the American right. New York: Pallgrave Macmillan, 2007.

HARDISTY, Jean. The Ressurgent Right: Why now?. The Public Eye. Fall/Winter 1995. Disponivel em: <http://www.publiceye.org/magazine/v09n3-4/ whynow.html> Acesso em 10/09/2012.

KIRK, Russell. The Conservative Mind: From Burke to Santayana. Chicago: Henry Regnery Company, 1953.

Edmund Burke and the Future of American Politics. The Russell Kirk Center. 1987. Disponivel em: <http://www.kirkcenter.org/index.php/ detail/burke-american-politics-1987/> Acesso em: 05/12/2012.

The American Cause. Wilmington: ISI Books; Kindle e-book, 2002. book, 2003.

The Roots of American Order. Wilmington: ISI Books; Kindle e-

LEVENDUSKY, Matthew. The Partisan Sort. Chicago: The University of Chicago Press, 2009.

MANN, Thomas E. e ORNSTEIN, Norman J. It's Even Worse Than It Looks. New York: Basic Books, 2012.

McCARTY, Nolan, POOLE, Keith T. e ROSENTHAL, Howard. Polarized America. London: The MIT Press, 2006.

NASH, George. The Conservative Intellectual Movement in America Since 1945. Wilmington: ISI Books; Kindle e-book, 2006.

NISBET, Robert. Still Questing. The Intercollegiate Review. Fall, 1993.

The Present Age: Progress and Anarchy in Modern America. Indianapolis: Liberty Fund, Inc, 2003.

Quest for Community: A Study in the Ethics of Order and Freedom. Wilmington, Delaware: ISI Books; Kindle e-book, 2010. 
O MOVIMENTO CONSERVADOR NORTE-AMERICANO DA DÉCADA DE 1950 E A PERCEPÇÃO CONSERVADORA A RESPEITO DA SOCIEDADE, ECONOMIA E POLIITICA EXTERNA

PEELE, Gillian e ABERBACH, Joel (ed.). Crisis of conservatism? The Republican Party, the Conservative Movement, and American Politics After Bush. Oxford: Oxford University Press, 2011.

PIERSON, Paul e HACKER, Jacob. Off Center: The Republican Revolution and the Erosion of American Democracy. New Haven: Yale University Press, 2005.

ROBIN, Corey. The Reactionary Mind: Conservatism from Edmund Burke to Sarah Palin. Oxford: Oxford University Press, 2011.

SCHOENWALD, Jonathan. A Time for Choosing: The Rise of the Modern American Conservatism. Oxford: Oxford University Press, 2001.

SOFFER, Reba. History, Historians and the Conservatism in Britain and America. Oxford: Oxford University Press, 2009.

STONECASH, Jeffrey M. (ed.) New Directions in American Political Parties. New York: Routledge, 2010.

SULliVAN, Andrew. The Conservative Soul. Harper Collins e-books, 2006.

THOMPSON, Michael. Confronting the New Conservatism: The rise of the right in America. New York: New York University Press, 2007.

VIDAL, Camila F. A Presença do Conservadorismo no Partido Republicano Norte-Americano. Dissertação de Mestrado apresentada ao PPGCP-UFRGS, 2013.

WEAVER, Richard. Las Ideas Tienen Consecuencias. Madrid: Ciudadelalibros; Kindle e-book, 2008.

Recebido em 10.10 .2013

Aprovado em 15.11.2013 